\title{
SPECIFICATION OF THE PROPERTIES AND EFFECTS OF ADDITIVES AND ADMIXTURES ON A MIXTURE SUITABLE FOR 3D PRINTING OF BUILDINGS
}

\author{
Diana FILAARSKÁ ${ }^{*}$, Stanislav UNČÍK ${ }^{1}$, PhD., Terézia CABANOVÁ ${ }^{1}$
}

\begin{abstract}
This article focuses on 3D printing of buildings using cement mortar-based material. Specific requirements are necessary for such a material; it therefore must have different properties compared to conventional cement mortar. These properties of a fresh mixture and the possibilities for their testing are described in more detail in the first part of the article. Specifically, these are pumpability, printability, buildability, and workability. In order to achieve these properties, it is necessary to add various additives and admixtures to the mixtures, in addition to the basic components such as water, sand, and cement. Scientists around the world are working to create an optimal mix. The second part of this article presents an overview of the most commonly used ingredients and their effect on the properties of the mixture.
\end{abstract}

Address

1 Dept. of Material Engineering, Faculty of Civil Engineering, Slovak University of Technology in Bratislava, Slovakia

* Corresponding author: diana.bladova@gmail.com

Key words

- 3D printing,

- Cement mortar,

- Additive manufacturing.

\section{INTRODUCTION}

Three-dimensional (3D) printing is an additive manufacturing technology that is gradually advancing in all major industries. Although it may seem like a modern technology, it originated in the 1980s. It is used on a daily basis in the healthcare, aerospace, automotive, and engineering industries. One industry that does not yet use this technology often is construction. The undeniable advantages of using 3D printing in construction include the reduction of labor and production of waste, the speed of construction, and freedom in architectural design. Of course, like any technology, in addition to its advantages, 3D printing has certain limitations and disadvantages, especially the implementation of reinforcement in the structure printed. Another disadvantage is the higher acquisition cost of a 3D printer. However, in the near future, these costs are expected to decrease in direct proportion to increases in competition in the market (Barnes et al., 1989). As 3D printing is currently only beginning to be used in construction industry, the aim of this article is to present examples of mixtures that are currently the subject of research. In addition, the properties that suitable mixtures must meet are specified.

\section{MIXTURE}

When designing a mixture suitable for 3D printing, we can use the pyramid graph shown below in Fig.1. This chart is known as a multi-level material design (MMD). It systematically shows some of the important steps from the selection of the raw materials to the design. The three pyramids of the MMD graph correspond to the three consecutive stages of mixture design, i.e., design of the mixture, the printing process, and the structure itself. These pyramids are connected by two peaks. The factors at the bottom three peaks of each pyramid greatly affect the properties at the top peak, which in turn significantly affects the higher level properties along with the other two factors (Lu et al., 2019).

At the lowest level / lowest pyramid, the various raw materials from which the mixture is formed contribute to the rheological properties of the material. These raw materials in this case are cement, a plasticizer, and a viscosity - enhancing additive (VEA). The rheology describes the deformation and flow characteristics of the material, which affect its pumpability and buildability during the printing process (Barnes et al., 1989). In addition to the rheology, the pumpability and buildability are also influenced by equipment-related parameters, such as the tribology (science of friction and wear of substances, parts 


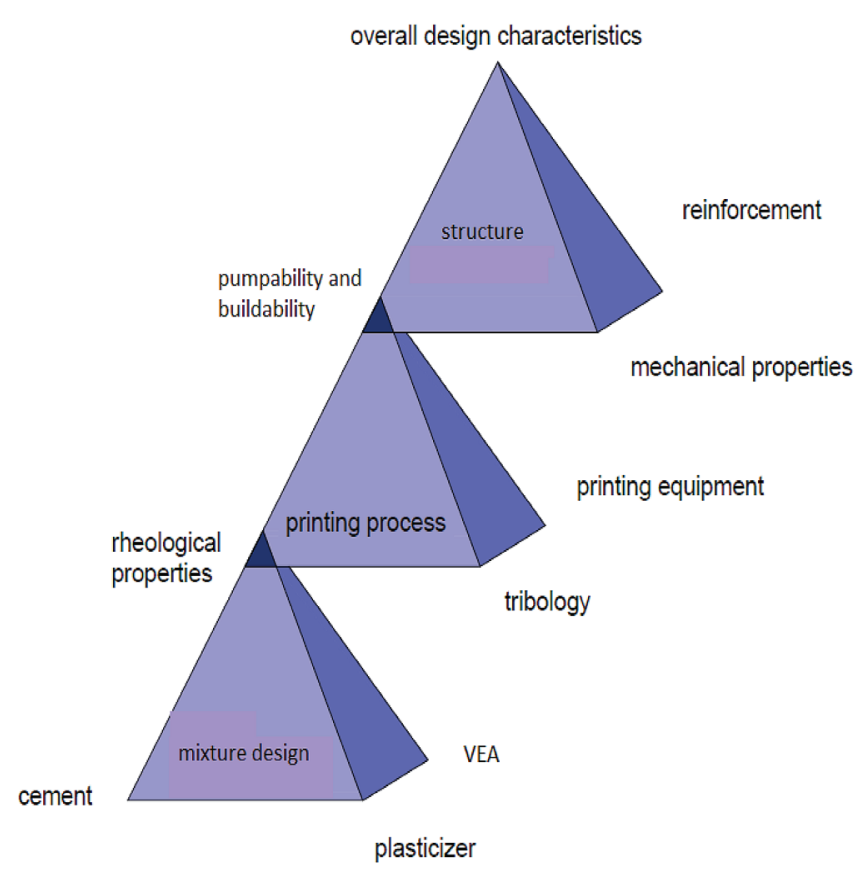

Fig. 1 Multi-level material design (Lu et al., 2019)

of machines, mechanisms, etc. (Yamagata, 2005), and the selection of the printing equipment itself (selection of the printhead, nozzle, pump, etc.). All these parameters are displayed in the middle level/ middle pyramid. The highest level/the last pyramid is the structure itself. At the very top of this pyramid are the properties of the structure as a whole. These properties are affected by the pumpability, buildability, mechanical properties, and reinforcement.

\section{REQUIRED CHARACTERISTICS}

The mortar mixture acts as an "ink" for the $3 \mathrm{D}$ printer. In order to be able to fulfill this function, it must have special properties. The properties can be divided into two categories, i.e., the properties of the fresh mixture and the properties of the hardened mixture (Fig. 2 ). We only achieve these properties by modifying the composition, respectively, by changing the ratio of the individual components.

One of the most important properties of a fresh mixture is its workability, which is related to the adhesion and stiffness of the individual layers. Other features are its pumpability, printability and buildability. The properties of the hardened mixture include the compressive

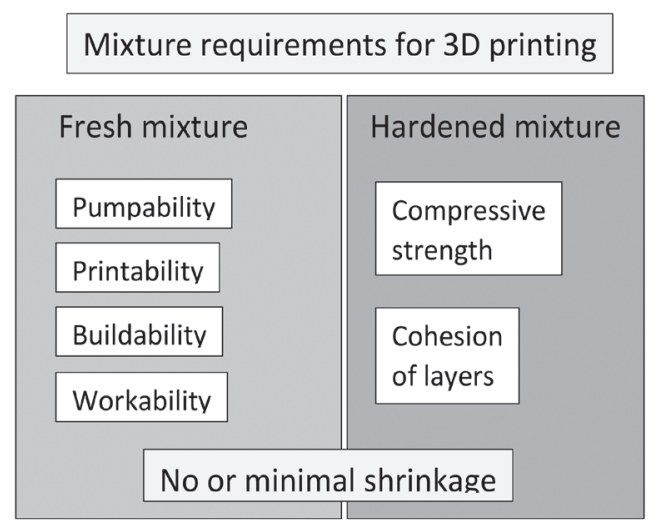

Fig. 2 Required characteristics (Nerella and Mechtcherine, 2019) strength, flexural strength, tensile strength and adhesion of the individual layers. As for shrinkage, it is not desired in any of the phases. If all of the requirements are met, constructions of various dimensions can be printed. Regarding the rheological properties of the mixture, the higher the viscosity and the lower the yield strength, the higher the plasticity and workability of the mixture. Some of the mentioned properties are described in more detail below (Nerella Mechtcherine, 2019).

\subsection{Pumpability}

One of the first steps in additive production is the transport of the mortar mixture through a pipe to the print head. This transfer is ensured by pumping using a pump. The pumpability of the mortar mixture depends to a large extent on its composition. Even a small change in composition can have a significant effect on the behavior of fresh material. Therefore, it is difficult to determine the quantitative ties between the composition of mixtures and their rheological properties (Nerella and Mechtcherine, 2019). It is clear that the rheological properties of concrete are crucial for its flow characteristics and largely determine the required pumping pressure (Feys et al., 2016). Only general quantitative estimates of the required pumping pressure are available, for example, by using nomograms and reograms. However, they have many technical and practical limitations, which have been described in detail in the literature (Feys et al., 2016; Wallevik and Wallevik, 2011). Therefore, various other approaches combining a wide range of experimental and numerical tools have been introduced and successfully validated (Wallevik and Wallevik, 2011; Kwon et al. 2016). One of them is the rheometer (Fig. 3).

The upper part of the rheometer is filled with the test mortar mixture and gradually pressed downwards. Subsequently, the pumpability of the mixture is expressed from the required pressure and the time during which the mixture is moved a certain distance (Nerella and Mechtcherine, 2019).

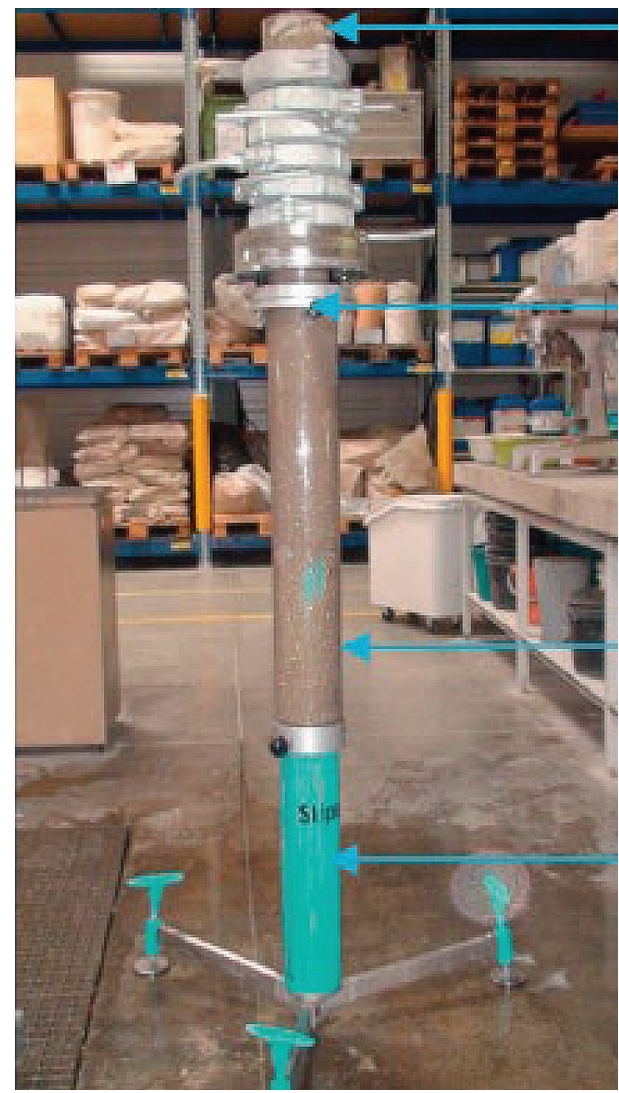

Fig. 3 Rheometer (Nerella and Mechtcherine, 2019) 


\subsection{Printability}

When the printable material reaches the print head, it should have a suitable degree of printability. Printability is defined differently. Le et al. defined it as "the ability of fresh concrete to pass through narrow pipes and nozzles in the printhead (Le et al., 2012)." Maleab et al. described printability as "the amount of concrete that can be continuously extruded through a nozzle (Malaeb et al., 2015)." A research team at the Technical University of Dresden (Nerella and Mechtcherine, 2019) defines printability as the ability of a material to be extruded through a print head nozzle with minimal energy requirements. Based on this definition, they developed a device for testing the printability of mixtures. The principle is the measurement of electric power consumption, on the basis of which the extrusion ability is subsequently evaluated.

\subsection{Buildability}

Buildability means the resistance to deformation of the printed layer against shear stress due to its own weight and the weight of the subsequently printed layers. The buildability largely depends on the development of the rheological properties of fresh cement mortar over time. Le et al. defined this property as the maximum number of printed layers that can be printed without plastic deformation of the lower layers (Le et al., 2012).

\subsection{Workability}

The workability of the mixture is important from the point of view of the bonding or interconnection of the individual successive layers. The processing time of the mixture must be alternated with respect to the size of the printed structure. After one layer is completely printed, the print nozzle returns to where it started. At that time, the cement mortar must have such properties that the next layer can be fully bonded with the previous one. At the same time, the mixture must be sufficiently hardened to be able to support the weight of the printed layers. Otherwise, it is highly likely that the structure will collapse (Fig. 4) (Buswell et al., 2018).

\section{COMPOSITIONS OF THE MIXTURE}

As mentioned above, a mortar mixture suitable for 3D printing of structures must have specific properties. The following chapter summarizes the various compositions or additives and admixtures with which the mortar mixtures have been modified in various studies.

\subsection{Modification of mixtures containing reinforcing fibers}

In order to reduce or eliminate the use of additional reinforcement in $3 \mathrm{D}$ printing, researchers have sought to create a mixture that would contain reinforcing fibers. Hambach et al. tested the mechanical properties of a mixture containing different fibers (carbon, glass and basalt). They found that the addition of $1 \%$ carbon fibers increased the flexural strength by $18.5 \mathrm{MPa}$, which in particular represented an improvement of $174.5 \%$ over the original mixture without added fibers. There was no significant change in the assessment of the compressive strength (Hambach and Volkmer, 2017).

Soltan et al. investigated the properties of both a fresh and a hardened fiber-reinforced mortar mixture. They found that the addition of hydroxypropylmethylcellulose could affect the initial flowability, but

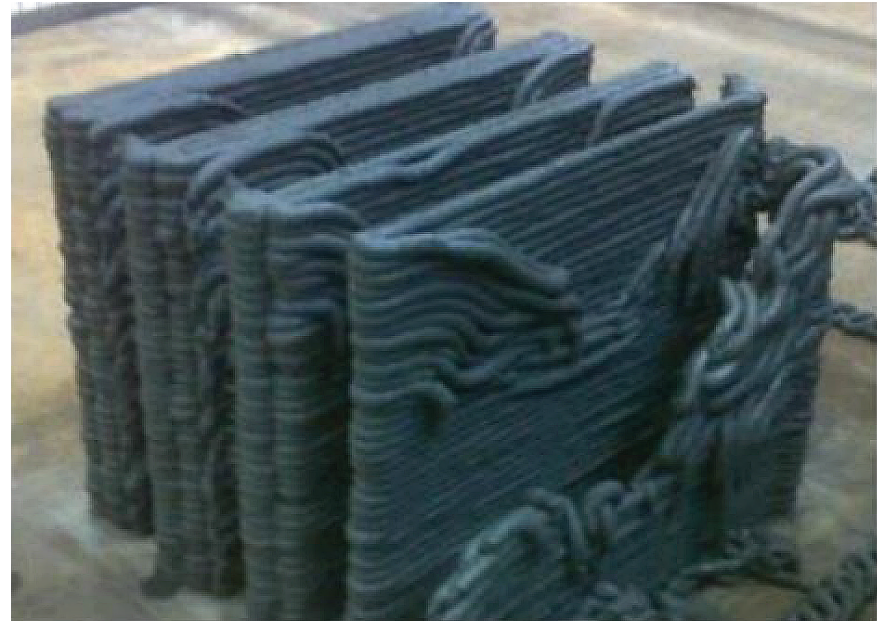

Fig. 4 Collapse of the printed structure (Buswell et al., 2018)

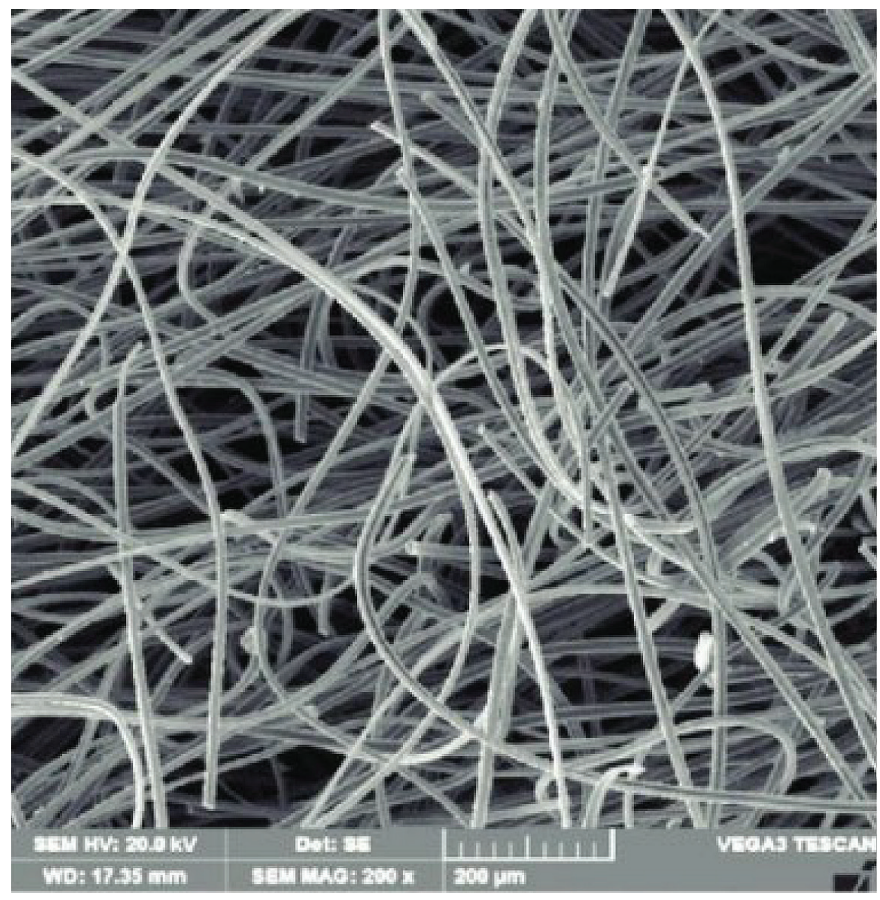

Fig. 5 Carbon-fiber (Marcuzzo et al., 2016)

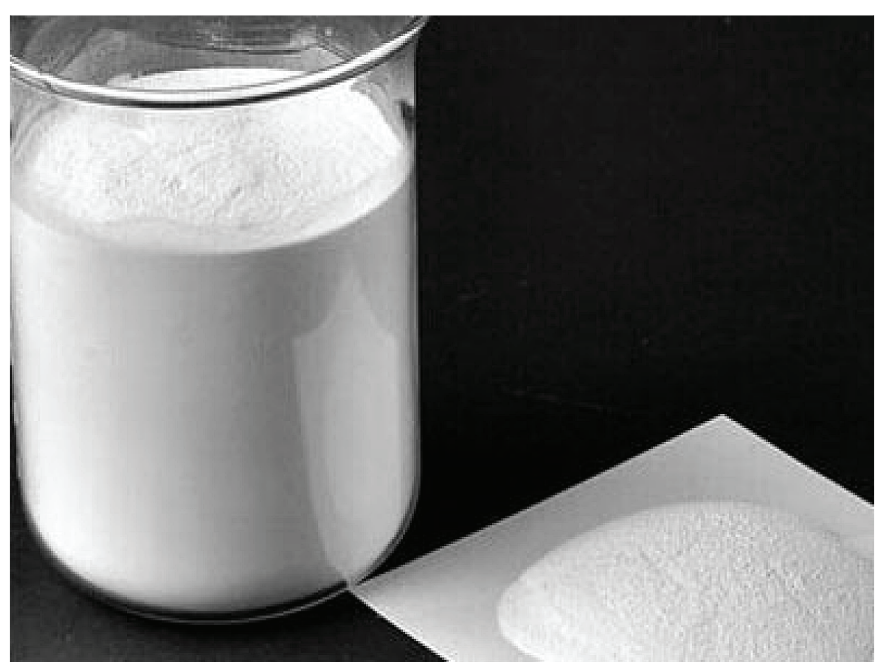

Fig. 6 Hydroxypropylmethylcellulose (Oh et al., 2015) 
not the rate of setting or hardening. Hydroxypropylmethylcellulose is mainly used in construction to extend the workability of mixtures. It is added to adhesives, self-leveling compounds, and also to cement (Oh et al., 2015; Soltan and Le, 2018).

Further research has focused on adding a small amount of nano-clay to a fiber-reinforced mortar mixture. The result was a reduction in the flowability of the mixture. Replacing a certain amount of silica sand with ground silica can increase the curing rate of fiber-reinforced cement composites, while maintaining their initial flowability. Furthermore, alumina cement, which proved to be effective both in increasing the initial flowability and also in increasing the hardening rate has been used. In this case, it was necessary to adjust the water content in the cement composites in order to achieve proper mixing and dispersion of the fibers, thus improving the mechanical properties (Zhang et al., 2019).

\subsection{Effect of a plasticizer and water coefficient}

Malaeb et al. examined mixtures without the addition of reinforcing fibers. In their research, they modified the mixtures by adding a plasticizer and changing the water content. They found that when the water-cement ratio is less than 0.42 , the addition of a plasticizer (0.95-2.5\% by weight of the water) can not only increase the compressive strength and flowability of cement composites, but also significantly reduce their buildability. With a water-cement ratio of 0.39 and a plasticizer content of $1.9 \%$, a wall with a height of $10 \mathrm{~cm}$ was built without any undesired deformation. In further research, they will focus on accelerators and inhibiters of hardening and setting of mixtures (Zhang et al., 2019).

\subsection{Effect of aggregates}

In $3 \mathrm{D}$ printing, it has been shown that the choice of aggregate also affects the properties of the mixtures.

Lin et al. concluded in their research that under the same pumping conditions, an aggregate with different grain sizes had no apparent effect on the extrusion of the mixture through the nozzle. Of course, it is necessary to observe the maximum permissible grain diameter with respect to the nozzle and the print head in order to avoid clogging. However, with a constant proportion of the other components of the mixture and with increasing the fineness of the ground sand, the flowability also increased, and the mechanical properties and the number of stable printed layers improved. On the other hand, the increased fineness reduced the viscosity of the mixture and the possible width of one layer (Lin et al., 2018).

Ma et al. tried to replace part of the aggregate in the mixture with copper tailings and achieved excellent results. Tailings are part of the

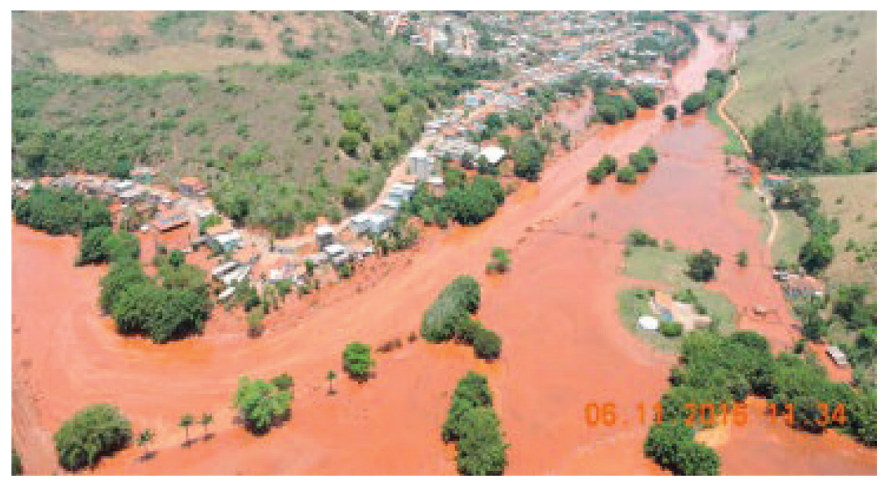

Fig. 7 Waste pollution after copper mining (Armo et al., 2018) waste generated during mining. They found that increasing the copper content increased the fluidity of the mixture. In this way, a large amount of non-degradable copper tailings could be used, which would have a positive impact on the environment (Guowei et al., 2018). Fig. 7 shows the pollution in Brazil by the waste just mentioned. Le et al. have also been partially involved in the addition of copper to mixtures and found that the optimal weight ratio of copper that replaces natural sand is $30 \%$. At the same time, they added a plasticizer to the mixture, which achieved excellent workability (Le et al., 2012).

\subsection{Influence of various additives and admixtures}

Rushing et al. (Rushing et al., 2019) tested various compositions of mixtures for printing and also performed tests, the results of which they processed in more detail.

The mixtures were divided into two groups, i.e., concrete and mortar. First, they designed a concrete mix, which they marked as A0. It contained traditional ingredients, i.e., cement, water, and aggregates and was selected as a starting mixture for the testing. The mixture included a CEM I to fine aggregate to coarse aggregate ratio of about 1:2:3. The coarse aggregate had a diameter of approximately $9.5 \mathrm{~mm}$. Other proposed mixtures are described in Tab. 1 (Rushing et al., 2019).

Tab. 1 Concrete mixtures A0 - A3 (Rushing et al., 2019)

\begin{tabular}{|l|l|}
\hline Designation of the mixture & Change in composition \\
\hline A0 & basic composition \\
\hline A1 & increase in cement dose \\
\hline A2 & addition of bentonite \\
\hline A3 & adding a plasticizer \\
\hline
\end{tabular}

\subsubsection{Extruder testing}

All the mixtures were subjected to an initial extrusion test. The printing took place through a square nozzle with an edge length of $44 \mathrm{~mm}$. The A0 mixture had a water content of 0.6 and was too stiff to pass through the nozzle. For this reason, modifications A1 - A3 were created, which should have had a better flow. Mixture A1 had a reduced water content of 0.47 , but was also not printable. Bentonite and a plasticizer were added to the A2 and A 3 mixtures in order to improve the flowability. Despite the improved properties, these blends also did not achieve the desired degree of printability. The reason was a high dose of the coarse aggregate with a large grain diameter that clogged the print head. Therefore, no further testing was performed on these mixtures (Rushing et al., 2019).

After sufficient fluidity had not been achieved with the concrete mixes, the scientists decided to significantly reduce the amount of the coarse aggregate and increase the amount of the fine aggregate. Thus, a ratio of cement and fine and coarse aggregates of 1: $3: 1$ was achieved. The water-cement ratio was 0.5 . Mixtures that mainly contain fine aggregates are called mortars. As with concrete mixes, the first mix was marked B0. The B1 - B6 mortar mixtures differed only by the addition of a certain component to the base mixture B0. Metal and nylon fibers, plasticizer, fly ash, and bentonite were added to the mixtures. Tab. 2 below shows changes in the composition that are specified (Rushing et al., 2019)

The mortar mixtures were also subjected to the same printability test as the concrete. Due to the reduction of the amount of coarse aggregate, all the mixtures were successfully forced through the nozzle. 
Tab. 2 B0 - B6 cement mortars (Rushing et al., 2019)

\begin{tabular}{|l|l|}
\hline $\begin{array}{l}\text { Designation of the } \\
\text { mixture }\end{array}$ & Change in composition \\
\hline B0 & basic composition \\
\hline B1 & addition of $12.5 \mathrm{~mm}$ long metal fibers \\
\hline B2 & addition of $12.5 \mathrm{~mm}$ long nylon fibers \\
\hline B3 & $\begin{array}{l}\text { adding a plasticizer } \\
\text { weight of the cement) }\end{array}$ \\
\hline B4 & addition of bentonite \\
\hline B5 & $\begin{array}{l}\text { addition of silica fume (replacement of } 10 \% \text { by } \\
\text { weight of the cement) }\end{array}$ \\
\hline B6 &
\end{tabular}

Tab. 3 Evaluation of printability of cement mortars BO - B6 (Rushing et al., 2019)

\begin{tabular}{|l|c|c|c|c|c|c|c|}
\hline Mixture & B0 & B1 & B2 & B3 & B4 & B5 & B6 \\
\hline Rating & 1 & 4 & 2 & 5 & 4 & 1 & 3 \\
\hline
\end{tabular}

Tab. 4 Evaluation of the spread of the BO - B6 cement mortars (Rushing et al., 2019)

\begin{tabular}{|l|c|c|c|c|c|c|c|}
\hline Mixture & B0 & B1 & B2 & B3 & B4 & B5 & B6 \\
\hline Rating & 3 & 2 & 2 & - & 1 & 4 & 5 \\
\hline
\end{tabular}

In Tab. 3, the individual mixtures are scored according to their printing ability $(1=$ worst printability, $5=$ best printability $)$.

Although the B3 mixture, which contained a plasticizer, was easily printable, its flowability was too high; thus the layer did not have sufficient dimensional stability after extrusion. Therefore, this mixture was excluded from further investigation. If they had wanted to think about it further, it would have been necessary to reduce the amount of water. The addition of metal fibers unexpectedly increased the flowability of the mixture, as the B1 mixture was extruded better when compared to the $\mathrm{B} 0$ base mixture. The $\mathrm{B} 2$ material containing nylon fibers was extruded better than the base mixture, but not better than the B1 mixture containing metal fibers. In general, the addition of fibers to the mixtures improved their flowability and also improved the dimensional stability of the extruded layer compared to the $\mathrm{B} 0$ base blend.

Replacing part of the Portland cement with fly ash (B4) and silica fume (B6) improved the printability compared to the B0 base mix. As for the B5 mixture, it was also necessary to increase the amount of water after the addition of bentonite, as the bentonite absorbed part of the water. Surprisingly, even after the addition of water, the bentonite did not help to improve the printability compared to the B0. However, the bentonite increased the dimensional stability of the extruded layer, which is also an important factor (Rushing et al., 2019).

\subsubsection{Drop table test}

In a drop table test, all the mortar mixtures marked B were tested, except for B3, which contained a plasticizer and did not have sufficient dimensional stability after extrusion. The test was performed using a Haegermann table (Fig. 8). Both the table surface and the conical form were moistened and filled with the mortar mixture in two layers, each compacted with 10 blows. The form was removed, and after 15 drops of the table, the average spread of the material was measured (Sičáková, 2020). Tab. 4 shows the test mixtures according

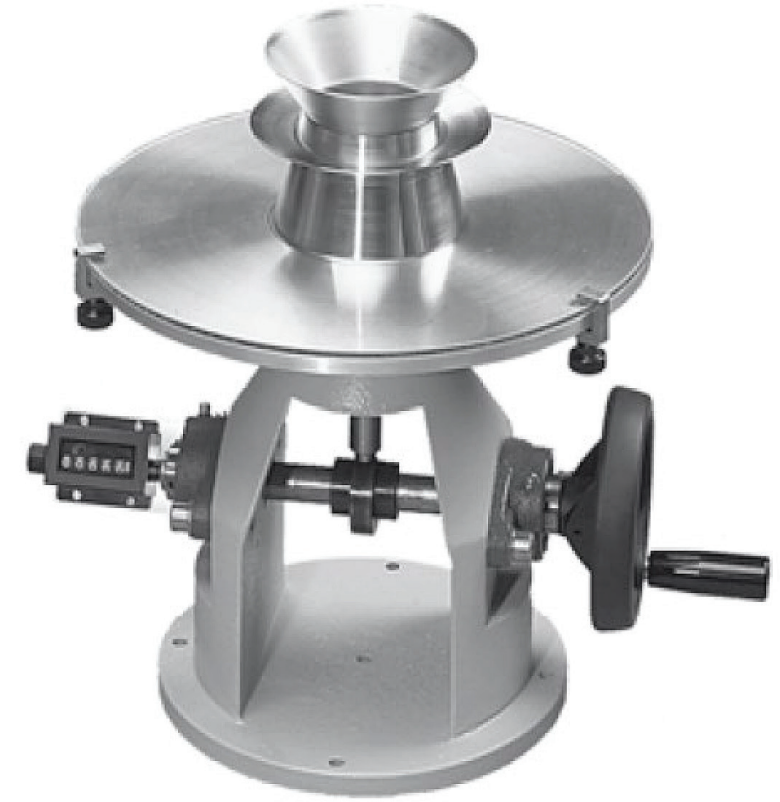

Fig. 8: Haegermann table for the slump test (Novanna monitoring systems)

to the size of the spread $(1=$ largest to $5=$ smallest spread $)$. The B4 fly ash mixture had the greatest spread. The B1 and B2 mixtures had fibers added. The smallest spreads were in the B5 and B6 mixture, which contained bentonite or silica fume (Rushing et al., 2019).

\subsubsection{Compressive strength test}

A compressive strength test was accomplished on all the mortar mixtures except B3. The tests were performed on cube-shaped samples with $50 \mathrm{~mm}$ long edge. The samples from the B1 and B2 mixtures, which contained fibers, were cylindrical in shape, i.e., 75 x $150 \mathrm{~mm}$. The compressive strength test was performed on days 1 and 7. The values given in Fig. 9 are average values from the 6 tested samples of the given mixture. As a rule, all the samples showed sufficient strength to be able to support the weight of the other printed layers. The lowest compressive strength was measured with the B2 mixture, which contained nylon fibers. The researchers say this may be due to the higher water content that needed to be added to improve workability. It can be seen in the table that the modified mixtures did not have increased compressive strength compared to the B0 base mixture. Nevertheless, it is necessary to modify the mixtures by combining different additives and admixtures to achieve other properties that a material suitable for $3 \mathrm{D}$ printing must have.

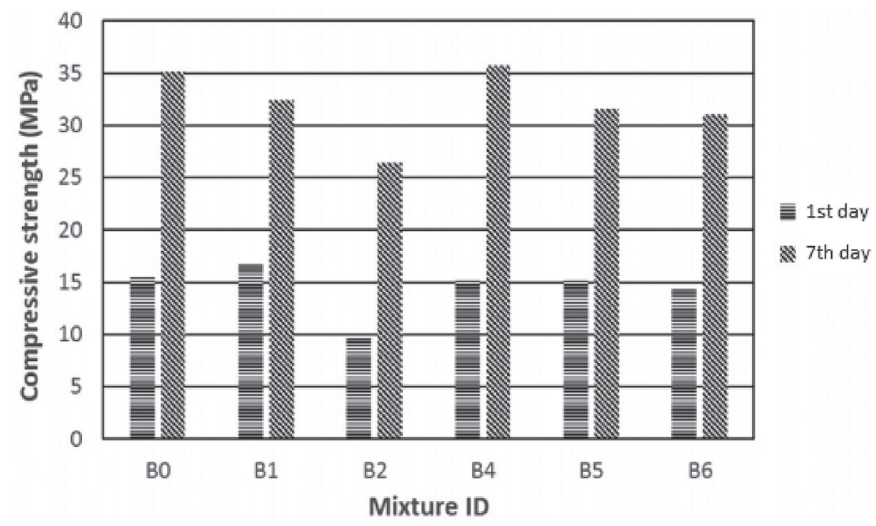

Fig. 9 Compressive strengths of the BO-B6 cement mortars (Rushing et al., 2019) 
Further experiments by Rushing et al. demonstrated the effect of various additives and admixtures on the workability time, development of the initial strength, and the static yield strength. The effects are shown in Tab.6 (Rushing et al., 2019)

Tab. 5 Summary of the effects of additives on the properties of mixtures (Rushing et al., 2019).

\begin{tabular}{|l|c|c|c|}
\hline Additive & $\begin{array}{c}\text { Workability } \\
\text { time }\end{array}$ & $\begin{array}{c}\text { Initial } \\
\text { strength }\end{array}$ & $\begin{array}{c}\text { Static yield } \\
\text { strength }\end{array}$ \\
\hline Accelerator & $\downarrow \downarrow$ & $\uparrow \uparrow$ & has not been tested \\
\hline $\begin{array}{l}\text { Recycled concrete } \\
\text { (used as aggregate) }\end{array}$ & $\downarrow$ & $\downarrow$ & $\leftrightarrow$ \\
\hline Plasticizer & $\uparrow \uparrow$ & $\downarrow$ & $\downarrow \downarrow$ \\
\hline Shrinkage reducer & $\leftrightarrow$ & $\downarrow$ & has not been tested \\
\hline Bentonite & $\downarrow \downarrow$ & $\leftrightarrow$ & $\uparrow \uparrow$ \\
\hline Fly ash & $\uparrow$ & $\downarrow$ & $\downarrow$ \\
\hline Silica fume & $\downarrow$ & $\downarrow \downarrow$ & $\uparrow \uparrow$ \\
\hline
\end{tabular}

Explanations:

$\uparrow \uparrow$ - high increase, $\uparrow$ - slight increase, $\downarrow \downarrow$ - high decrease, $\downarrow$ - slight decrease, $\leftrightarrow$ - no change

\section{CONCLUSION}

The subject of this article was to present the issue of $3 \mathrm{D}$ printing in construction. The article specifies and points out the special properties that a material suitable for 3D printing must meet. At the same time, the article summarizes the results of research concerning the composition of the extruded mixture, i.e., cement mortar. The results are from different studies on which different teams of researchers are working. Most often, the composition is a modification of mixtures with additives and admixtures. Mixtures containing reinforcing carbon fibers, which reduced the flowability with the addition of hydroxypropylmethylcellulose, were tested. On the other hand, the use of alumina cement increased the fluidity. In further research, the effect of the type and size of the aggregate was tested, as well as the effect of the properties by changing the water coefficient. Finally, in the research, which took place under the guidance of Professor Rushing, additives and admixtures were used to change the properties. Changes in the diameter of the spread, printability, workability and, last, but not least, in the compressive strength were observed, which is of great importance in the design of mainly load-bearing structures. Three-dimensional printing has great potential for use in the construction industry. In order to be able to at least partially replace conventional construction methods, it will have to mainly overcome the limitations mentioned in the introduction of the article. At present, 3D printing is already used in developing countries for rapid housing construction. 


\section{REFERENCES}

Armo, F. - Kamino, L. - Campos, I. (2017) Fundão tailings dam failures: the environment tragedy of the largest technological disaster of Brazilian mining in global context, Perspectives in Ecology and Conservation, Vol. 15, No. 3, pp. 145-151, ISSN 2530-0644, https://doi.org/10.1016/j.pecon.2017.06.002

Barnes. H. - Hutton, J. - Walters, K. (1989) An Introduction to Rheology, Elsevier, Amsterdam, The Netherlands; New York, U.S.

Buswell, R. - Leal de Silva, W. - Jones, S. - Dirrenberger, J. (2018) $3 D$ printing using concrete extrusion: A roadmap for research, Cement and Concrete Research, Vol. 112, pp. 37-49, ISSN 00088846, https://doi.org/10.1016/j.cemconres.2018.05.006

Feys, D. - Khayat, K. - Khatib, R. (2016) How do concrete rheology, tribology, flow rate and pipe radius influence pumping pressure?, Cement and Concrete Composites, Vol. 66, pp. 38-46, ISSN 0958-9465, https://doi.org/10.1016/j.cemconcomp.2015.11.002

Guowei, M. - Zhijian, L. - Li, W. (2018) Printable properties of cementitious material containing copper tailings for extrusion based $3 D$ printing, Construction and Building Materials, Vol. 162, pp. 613-627, ISSN 0950-0618, DOI: https://doi.org/10.1016/j. conbuildmat.2017.12.051

Hambach, M. - Volkmer, D. (2017) Properties of 3D-printed fiber-reinforced Portland cement paste, Cement and Concrete Composites, Vol. 79, pp. 62-70, ISSN 0958-9465, https://doi. org/10.1016/j.cemconcomp.2017.02.001

Kwon, S. - Jang, K. - Kim, J. - Shah, S. (2016) State of the Art on Prediction of Concrete Pumping, International Journal of Concrete Structures and Materials, 10, pp. 75-85, DOI: $\underline{10.1007 /}$ s40069-016-0150-y

Le, T. - Austin, S. - Lim, S. (2012) Mix design and fresh properties for high-performance printing concrete, Materials and Structures 45, pp. 1221-1232, DOI: https://doi.org/10.1617/s11527-012-9828-Z

Lin, J. - Wu, X. - Yang, W. (2018) The influence of fine aggregates on the $3 D$ printing performance, IOP conference series: Materials Science and Engineering, Vol. 292, pp. 012-079

Lu, B. - Weng, Y. - Li, M. - Qian, Y. - Leong, K. - Tan, M. (2019) $A$ systematical review of $3 D$ printable cementitious materials, Construction and Building Materials, Vol. 207, pp. 477-490, ISSN 0950-0618, https://doi.org/10.1016/j.conbuildmat.2019.02.144

Malaeb, Z. - Hachem, H. - Tourbah, A. - Maalouf, T. - Zarwi, N. - Hamzeh, F. (2015) 3D Concrete Printing: Machine and Mix Design, International Journal of Civil Engineering and Technology, Vol. 6, pp. 14-22
Marcuzzo, J. - Cuna, A. - Heide, B. (2016) Microporus activated carbon fiber felt from Brazilian textile PAN fiber: preparation, characterization and application as super capacitor electrode. Revista Brasileira de Aplicações de Vácuo

Nerella, V. - Mechtcherine, V. (2019) Chapter 16 - Studying the Printability of Fresh Concrete for Formwork-Free Concrete Onsite 3D Printing Technology (CONPrint3D), 3D Concrete Printing Technology, Butterworth-Heinemann, pp. 333-347, ISBN 9780128154816, https://doi.org/10.1016/B978-0-12-8154816.00016-6

Oh, C. - Heng, P. - Chan, L. (2015) A Study on the Impact of Hydroxypropyl Methylcellulose on the Viscosity of PEG Melt Suspensions Using Surface Plots and Principal Component Analysis, AAPS PharmSciTech 16, pp. 466-477 DOI: https://doi. org/10.1208/s12249-014-0204-X

Rushing, T. - Stynoski, P. - Barna , L. - Al-Chaar, G. - Burroughs, J. - Shannon, J. - Kreiger, M. - Case, M. (2019) Chapter 7 Investigation of Concrete Mixtures for Additive Construction, 3D Concrete Printing Technology, Butterworth-Heinemann, pp. 137160, ISBN 9780128154816, DOI: https://doi.org/10.1016/B978$\underline{0-12-815481-6.00007-5}$

Soltan, D. - Li, V.: A self-reinforced cementitious composite for building-scale $3 D$ printing, Cement and Concrete Composites, Vol. 90, 2018, pp. 1-13, ISSN 0958-9465, DOI: https://doi.org/10.1016/j. cemconcomp.2018.03.017

Wallevik, O. - Wallevik, J. (2011) Rheology as a tool in concrete science: The use of rheographs and workability boxes, Cement and Concrete Research, Vol. 41, No. 12, pp. 1279-1288, ISSN 0008-8846, https://doi.org/10.1016/j.cemconres.2011.01.009

Zhang, J. - Wang, J. - Dong, S. - Yu, X. - Han, B. (2019) A review of the current progress and application of $3 D$ printed concrete, Composites Part A: Applied Science and Manufacturing, Vol. 125, 105533, ISSN 1359-835X, https://doi.org/10.1016/j.compositesa.2019.105533

Yamagata, H. (2005) 2 - The cylinder, The Science and Technology of Materials in Automotive Engines, pp. 10-52, ISBN 9781855737426, https://doi.org/10.1016/j.compositesa.2019.105533

Novanna monitoring systems,Novanna, available at: https://www. novanna.co.uk/hagermann-flow-table (last visited 8.12.2020)

Sičáková, A. (2020) Skúška rozliatím, Materiálové inžinierstvo, TUKE, available at: $\underline{h t t p s: / / s i t e s . g o o g l e . c o m / s i t e / s v f m a t e r i a l o v e i n z i n i e r s t-~}$ vo/stavebne-materialy/ucebne-texty/skky-erstvho-betnu/konzistencia-erstvho-betnu/skka-rozliatm (last visited 8.12.2020) 